\title{
CD127 expression in peripheral T cells of pediatric kidney transplant recipients
}

\author{
Doaa M. Salah', Manal F. Elshamaa², Eman A. Elghoroury ${ }^{3}$, Neemat M.A. Kassem4, Hafez M. \\ Bazaraa', Mona F. Ibrahim ${ }^{3}$, Ashraf Galal' ${ }^{2}$, Fatina I. Fadel ${ }^{1}$ \\ 'Department of Pediatrics, Faculty of Medicine, Cairo University, Cairo, Egypt \\ 2Department of Pediatrics, National Research Centre, Cairo, Egypt \\ ${ }^{3}$ Departments of Clinical Pathology, National Research Centre, Cairo, Egypt \\ ${ }^{4}$ Oncology Department, Faculty of Medicine, Cairo University, Cairo, Egypt
}

\section{ABSTRACT}

Introduction: Regulatory $\mathrm{T}$ cells (Treg) are emerging as a potential therapy to facilitate long-term allograft survival what makes identification of reliable surface markers that are selectively expressed on Treg is crucial. The aim of this study is to evaluate the regulatory and suppressive functions of CD127 in peripheral T lymphocytes of pediatric kidney transplant recipients through studying the association their frequency and the development of rejection.

Material and methods: Flow cytometric analysis of peripheral blood samples for the CD127 surface marker of 50 pediatric transplant recipients and 12 healthy controls was done. Clinical, laboratory, immunosuppressive therapy data and graft function of transplant recipients were collected and correlated with their CD127 peripheral blood expression.

Results: CD127 expression in transplanted children was significantly elevated than that of controls (2.76 $\pm 3.26 \%$ vs. $0.95 \pm 0.94 \%, p=0.042)$. CD 127 expression did not correlate with donor relation, cytomegalovirus infection, acute rejection episodes or type of immunosuppressive drugs ( $p=0.475,0.479,0.678$ and 0.333 respectively). Patients with chronic allograft dysfunction (CAD) had significantly lowered frequencies of CD127 compared with those with stable graft function $(0.61 \pm 0.549 \%$ vs. $3.08 \pm 3.375 \%, p=0.021)$.

Conclusions: CD127+ cells is more expressed in transplanted children with stable graft function than those with CAD which makes the regulatory role of CD127+ cells post-transplantation a subject for further researches. The negative relationship between the frequency of CD127 and CAD supposes these cells as probable candidates for allowing allograft survival.

KEY WORDS:

CD127, chronic rejection, regulatory $\mathrm{T}$ cells, transplantation, children.

\section{INTRODUCTION}

Although kidney transplantation (KT) is the preferred treatment for end-stage renal disease (ESRD) in children, the occurrence of rejection is a dominant risk factor for adverse graft outcome [1]. Understanding the mechanisms of rejection and tolerance can lead to the develop- ment of new non-invasive methods to monitor the immune response in children after $\mathrm{KT}$.

CD4+CD25+Foxp3+ T cells are now widely considered to be the classic Treg population. Foxp3 is an intracellular molecule, detection of which requires fixation and permeabilization of cells. The fixed cells cannot be used in studies of Treg function. So, finding a specific cell surface marker of Treg cells is mandatory for further

\section{ADDRESS FOR CORRESPONDENCE:}

Manal F. Elshamaa, Pediatrics Department, National Research Centre, Cairo, Egypt, e-mail: manal_elshmaa@ hotmail.com 
study [2]. In many studies, CD127 (IL7 receptors) expression in CD4+CD25+ cells was correlated inversely with FoxP3 expression, and CD4+CD25+CD127 cells showed suppressive activity [3-5]. Previous data suggested that the CD127 biomarker can be used to more selectively enrich human Treg cells for further in vitro and in vivo studies [6]. However, the clinical significance of changes in percentages of circulating CD4+ regulatory $\mathrm{T}$ cells after transplantation is not yet clear and needs further studies. In the present work, we aimed to study the percentage of CD127 in peripheral T cells of pediatric kidney transplant recipients by flow cytometry and to detect the association between CD127 surface marker and the development of rejection among this group of patients.

\section{MATERIAL AND METHODS}

The study included fifty pediatric kidney transplant recipients recruited from the Kidney Transplantation Outpatient Clinic, Cairo University Children's Hospital (CUCH). Twelve healthy children who attended the Pediatric Clinic of the Medical Research Centre of Excellence (MRCE), National Research Centre (NRC) with no clinical signs or family histories of renal disease were included for comparison of measured lymphocyte subset values. The study was conducted from 2014 to 2017 . Kidney transplant recipients showing signs of ureteral obstruction and/or renal artery stenosis of the graft, arterial, venous thrombosis, and infection-induced fever were excluded from the study. The time elapsed from the time of transplantation to the point of the study was $2.54 \pm 1.35$ years (range $0.5-6$ years). Peripheral blood samples were obtained from KT recipients.

\section{ETHICAL ISSUES}

All included patients' guardians gave informed written consent before participating in the study, which was read and approved by the Ethics Committee of NRC in Egypt.

\section{IMMUNOSUPPRESSIVE (IS) REGIMENS}

Antibody induction therapy was used in 46 patients, while 4 patients did not receive antibody induction immunosuppression. IL-2 receptor blocking antibody (basiliximab) was administrated in 12 patients while anti-thymocyte globulin (ATG) was administrated in 34 patients. All children received intravenous methylprednisolone perioperative as a part of induction immunosuppressive therapy. Steroids then gradually tapered to oral prednisolone after the first week that was tapered down to $2.5-7.5 \mathrm{mg} /$ day by the first year of transplantation. In addition to steroids; immunosuppressive protocol included calcineurin inhibitor (CNI) and mycophenolate mofetil (MMF). Tacrolimus was the CNI used in 32 patients while cyclosporine (CsA) was given in 18 patients. Mycopheno- late mofetil was administrated as an adjuvant therapy to all patients for at least one-month post-transplantation then continued in 46 patients afterward. Everolimus was administered in 4 patients (in combination with steroids and low dose CsA) after at least one-month post-transplantation.

\section{CLINICAL AND LABORATORY PARAMETERS}

The donor relation (related vs. unrelated), acute rejection (AR) episodes, cytomegalovirus (CMV) infection, CsA/ tacrolimus trough serum concentrations, and current graft function were reviewed. Cold ischemia time was defined as the Time elapsed between clamping of donor graft artery and de-clamping of the anastomosing vessel in the recipient (signifies the duration of ischemia/reperfusion injury). AR was defined as a rise in serum creatinine of 20-30\% from baseline levels and accompanied by clinical symptoms and signs as fever (temperature of more than $37.5^{\circ} \mathrm{C}$ ), graft tenderness, and oliguria [7]. Presumed acute rejection (PRAR) was defined as an episode of AR, which is clinically diagnosed and medically treated (by pulse methylprednisolone), but a biopsy sample was not taken or did not show signs of rejection according to the Banff criteria [8]. Biopsy proven acute rejection (BPAR) was defined as acute graft dysfunction associated with pathological evidence of rejection.

Chronic allograft dysfunction (CAD) was defined clinically as a progressive deterioration of graft function with $\geq 15 \%$ irreversible rise in creatinine within 1 to 3 months and proteinuria $\geq 1 \mathrm{~g} / 24 \mathrm{~h}$ together with a histologic diagnosis of interstitial fibrosis and tubular atrophy (IFTA) [9]. Patients with chronic antibody-mediated rejection (cAMR) were defined as patients having progressive allograft dysfunction (rise of creatinine and/or proteinuria $\geq 0.5 \mathrm{~g} / \mathrm{d}$ ) over recent months, together with evidence of circulating donor-specific antibodies and a biopsy-proven diagnosis of cAMR (based on the Banff'07 criteria [10] with detection of C4d in peritubular capillaries. From the 7 patients with $\mathrm{CAD}$, one patient was diagnosed with cAMR and 6 patients were diagnosed with chronic allograft nephropathy.

\section{FLOW CYTOMETRIC ANALYSIS}

Fresh blood samples on EDTA (100 Ul) with monoclonal antibodies were incubated $20 \mathrm{~min}$ at room temperature in the dark. Samples were lysed with $0.5 \mathrm{ml}$ lysing solution Optilyse C (Beck man Coulter, Brea, CA, USA) $10 \mathrm{~min}$ the room temperature in the dark. Lysing reaction was stopped with $1 \mathrm{ml}$ Cell Wash (optimized PBS) (Beck ton Dickinson Bioscience, Benelux, Belgium), the pellet was suspended in PBS and kept in dark between 2 and $8^{\circ} \mathrm{C}$. Samples were measured on an FC 500 flow cytometer (Beck man Coulter, Brea, CA, USA). Gating strategy: As described before $[11,12]$ cells were gated by side scatter and CD4 expression. Subsequently, CD127 was measured on the cell surfac- 
TABLE 1. Demographic, clinical and laboratory data of transplanted patients $(n=50)$ and their correlation to CD127\%

\begin{tabular}{|c|c|c|c|}
\hline & Mean \pm SD & CD127 (Pvalue) & CD127 (correlation coefficient) \\
\hline Age at Tx (years) & $10.36 \pm 3.84$ & 0.322 & 0.146 \\
\hline Age at Assessment (years) & $12.94 \pm 4.23$ & 0.159 & 0.207 \\
\hline Post Tx FU duration (months) & $30.94 \pm 16.51$ & 0.591 & 0.080 \\
\hline Pre-Tx dialysis duration (months) & $21.70 \pm 25.34$ & 0.479 & 0.105 \\
\hline Wt. at assess (kg) & $38.50 \pm 14.93$ & 0.085 & 0.251 \\
\hline $\mathrm{Ht}$. at assess $(\mathrm{cm})$ & $129.94 \pm 16.99$ & 0.763 & 0.045 \\
\hline BMl at assess $\left(\mathrm{kg} / \mathrm{m}^{2}\right)$ & $22.63 \pm 7.88$ & 0.190 & 0.324 \\
\hline $\mathrm{SBP}(\mathrm{mm} \mathrm{Hg})$ & $109.40 \pm 10.50$ & 0.079 & 0.256 \\
\hline $\mathrm{DBP}(\mathrm{mmHg})$ & $70.40 \pm 8.91$ & 0.047 & 0.288 \\
\hline Donor Age (years) & $37.18 \pm 6.21$ & 0.251 & 0.169 \\
\hline Cold ischemia time (minutes) & $52.45 \pm 12.30$ & 0.378 & 0.132 \\
\hline PRD dose at 1 month (mg/day) & $19.02 \pm 5.44$ & 0.054 & 0.292 \\
\hline PRD dose at 12 months (mg/day) & $4.23 \pm 1.55$ & 0.299 & 0.155 \\
\hline Trough CsA (ng/ml) & $110.83 \pm 18.55$ & 0.913 & -0.058 \\
\hline Trough Tacrolimus (ng/ml) & $6.26 \pm 1.16$ & 0.958 & 0.015 \\
\hline $\mathrm{GFR}\left(\mathrm{ml} / \mathrm{min} / 1.73 \mathrm{~m}^{2}\right)$ & $76.20 \pm 22.10$ & 0.646 & -0.068 \\
\hline $\mathrm{Hb}(\mathrm{gm} / \mathrm{dl})$ & $10.84 \pm 1.17$ & 0.497 & -0.122 \\
\hline HCT & $32.14 \pm 4.20$ & 0.040 & -0.359 \\
\hline $\mathrm{TLC}\left[\times 10^{3} / \mathrm{mm}^{-3}\right]$ & $7.83 \pm 2.61$ & 0.372 & -0.161 \\
\hline $\mathrm{G}$ count $\left[\times 10^{3} / \mathrm{mm}^{-3}\right]$ & $49.70 \pm 17.15$ & 0.624 & 0.093 \\
\hline$L$ count $\left[\times 10^{3} / \mathrm{mm}^{-3}\right]$ & $37.07 \pm 16.64$ & 0.603 & -0.099 \\
\hline PLT count $\left[\times 10^{3} / \mathrm{mm}^{-3}\right]$ & $223.06 \pm 78.41$ & 0.659 & -0.080 \\
\hline
\end{tabular}

Tx - transplantation; FU - follow up; Wt. - weight; Ht. - height; BMI - body mass index; SBP - systolic blood pressure; DBP - diastolic blood pressure; PRD - prednisolone; CSA - cyclosporine; HB - hemoglobin; GFR - glomerular filtration rate; Hct - hematocrit; MCV - mean corpuscular volume; $M C H$ - mean corpuscular hemoglobin; $M C H C$ - mean corpuscular hemoglobin concentration; TLC - total leucocyte count; $G$ - granulocyte count; $L$-lymphocyte count; $P L T$ - platelet count

${ }^{*} P<0.05$ was considered significant.

es. A flow cytometry analysis was performed with at least 100 events in the gate. The frequency of CD127 is expressed as a percentage of peripheral blood mononuclear cells (PBMCs).

\section{STATISTICAL ANALYSIS}

Data were tabulated and subjected to computer-assisted statistical analysis using SPSS version 16.0. Nominal data will be described as frequency and percentage and compared using $\chi^{2}$ tests. Numerical data were described as a mean and a standard deviation and compared using the Student $t$-test. Correlation between various variables was done using the Spearman rank correlation equation. Nonparametric data were compared using Mann-Whitney and Kruskal-Wallis Tests. ANOVA post hoc test was used for multiple comparisons. Accuracy was represented using the terms sensitivity and specificity. Receiver operator characteristic (ROC) analysis was used to determine the optimum cut-off value for the IL-7R level in predicting active rejection. Logistic regression was done to detect independent predictors of the CAD. A p-value less than 0.05 was considered significant.

\section{RESULTS}

\section{PATIENT CHARACTERISTICS}

The mean age of the study group was $10.36 \pm 3.84$ years with the mean post-transplantation (post-Tx) duration of $30.9 \pm 16.5$ months. The male/female ratio was $35 / 15$. The original renal disease was obstructive uropathy in 18 patients (36\%), inherited nephropathy in 14 patients (28\%), unknown in 14 patients (28\%), and chronic glomerulopathy in 4 patients (8\%). All included patients received living donor kidney transplant [related $($ LRKT)/unrelated $(\mathrm{LUKT})=4 / 1$ ] . All patients received their first renal transplant except 1 patient with a previously failed graft due to venous thrombosis. All included recipients were negative for HIV ab, HBV surface antigen before KT; eleven (22\%) recipients were $\mathrm{HCV}$ ab positive after receiving antiviral treatment (interferon) with low-grade viremia as tested by RT-PCR study at the time of transplantation. CMV IgG was positive for donors and recipients in 44 patients, negative for both in 4 cases, and negative recipients received from positive donors in 2 patients. 


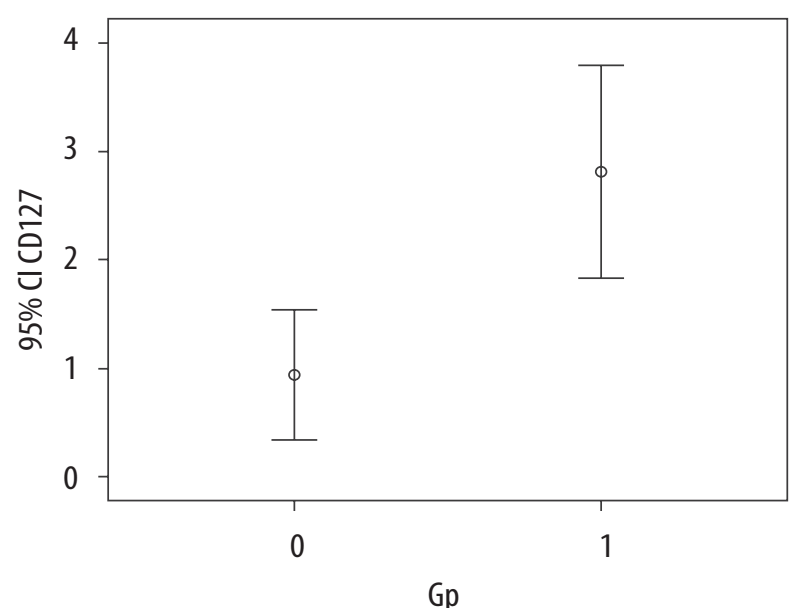

FIGURE 1. Percentage of CD127 in (mean \pm SD). The percentage of CD127 in transplanted children was significantly higher as compared with healthy controls $(2.76 \pm 3.26 \%$ vs. $0.95 \pm 0.94 \%$, $p=0.042)$. The frequency of CD127 is expressed as a percentage of peripheral blood mononuclear cells (PBMCs). $P$-value $<0.05$ was considered significant

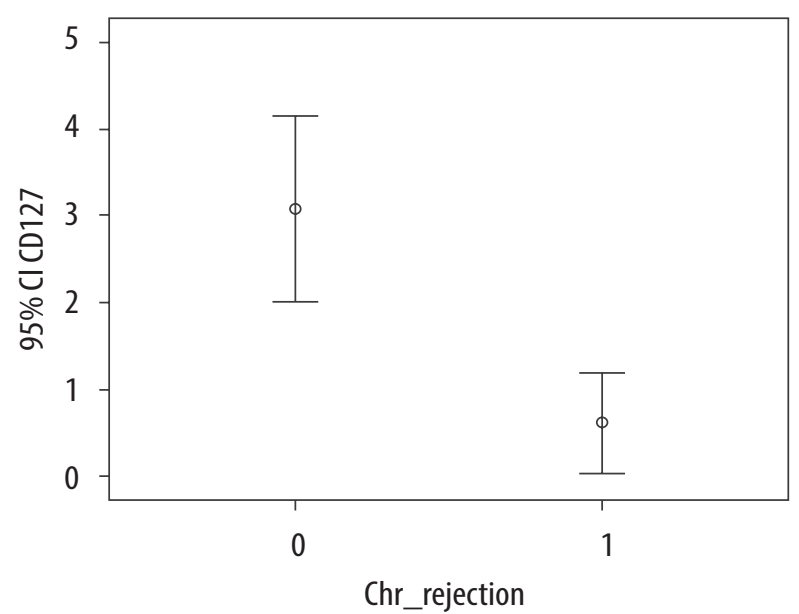

FIGURE 2. The association between the frequency of T cell activation marker, i.e., CD127\% and CAD in kidney transplant recipients. The frequency of $C D 127$ is expressed as a percentage of peripheral blood mononuclear cells (PBMCs). There is a significant association between circulating CD127 and the CAD $(0.61 \pm 0.549 \%$ vs. 3.08 $\pm 3.375 \%, p=0.021)$. $P$-value $<0.05$ was considered significant

Demographic, clinical characteristics, and laboratory data of transplanted patients are summarized in Table 1.

The mean CD127 expression of transplanted patients was significantly elevated than that of controls $(2.76$ $\pm 3.26 \%$ vs $0.95 \pm 0.94 \%, \mathrm{p}=0.042$ ) (Figure 1 ).

\section{THE ASSOCIATIONS BETWEEN THE PERCENTAGE OF CD127 AND THE CLINICAL-LABORATORY PARAMETERS}

Significant positive correlation was found between CD127 expression and diastolic blood pressure (DBP) $(p=0.047, \mathrm{CI}=0.288) . \mathrm{CD} 127 \%$ negatively correlated with hematocrit $(p=0.04, r=-0.359)$. In addition; no significant association was found between CD127 expres-
TABLE 2. Comparisons of the lymphocyte surface marker (CD127) with different subgroups of transplanted patients $(n=50)$

\begin{tabular}{|l|c|c|}
\hline & Mean \pm SD & P-value \\
\hline \begin{tabular}{l} 
Donor relation \\
\hline Related donor
\end{tabular} & 0.475 \\
\hline Nonrelated donors & $2.80 \pm 3.52$ & \\
\hline \begin{tabular}{l} 
Antibody induction therapy* \\
\hline ATG $(n=34)$
\end{tabular} & $2.61 \pm 2.24$ & \\
\hline Basiliximab $(n=12)$ & $2.05 \pm 3.24$ & \\
\hline No antibody induction $(n=4)$ & $2.70 \pm 3.08$ & \\
\hline IS protocol & & 0.090 \\
\hline CsA based protocol $(n=14)$ & $2.85 \pm 2.49$ & \\
\hline Tacrolimus based protocol $(n=32)$ & $2.63 \pm 3.60$ & \\
\hline m-TORI low (sA protocol $(n=4)$ & $3.68 \pm 5.12$ & \\
\hline \begin{tabular}{l} 
CNI used \\
\hline CsA ( $n=18)$
\end{tabular} & & 0.341 \\
\hline Tacrolimus $(n=32)$ & $2.85 \pm 2.49$ & \\
\hline CMV status & $2.72 \pm 3.67$ & \\
\hline CMV RT-PCR $(-)(n=40)$ & $2.79 \pm 3.30$ & \\
\hline CMV RT-PCR $(+)(n=10)$ & $2.64 \pm 3.28$ & \\
\hline \begin{tabular}{l} 
PRAR episodes\# \\
\hline No PRAR $(n=17)$
\end{tabular} & & 0.976 \\
\hline 1 episode PRAR $(n=9)$ & $2.55 \pm 4.70$ & \\
\hline$\geq 2$ episodes PRAR $(n=24)$ & $2.46 \pm 2.25$ & \\
\hline Yes BPAR $(n=33)$ & & 0.678 \\
\hline
\end{tabular}

ATG - antithymocyte globulin; IS - immunosuppression; CNI - calcineurin inhibitor; CSA - cyclosporine; $m$-TORI - mammalian target of rapamycin inhibitors; $C M V$ - cytomegalovirus; $R T-P C R$ - real time-polymerase chain reaction; PRAR - presumed acute rejection; BPAR - biopsy-proven acute rejection

${ }^{*}$ No significant difference was found in CD127 expression on comparing ATG vs. no antibody induction groups (2.05 \pm 3.24 vs. $2.70 \pm 3.08$ with $p=0.123)$, ATG vs. basiliximab groups (2.05 \pm 3.24 vs. $4.16 \pm 2.95$ with $p=0.578)$ and basiliximab vs. no antibody induction groups $(4.16 \pm 2.95$ vs. 2.70 \pm 3.08 with $p=0.053$ ).

\# No significant difference was found in CD127 expression on comparing no PRAR episodes cases vs. cases with single PRAR episode $(p=0.935)$ nor vs. cases with $\geq 2$ episodes $(p=0.743)$, nor between cases of single PRAR episode vs. cases with $\geq 2$ episodes $(p=0.970)$. $P$-value was significant if $<0.05$.

sion and any of demographic, other clinical, or laboratory data listed in Table 1.

As illustrated by Table 2; donor relation, CMV status, immunosuppressive medications and AR episodes (either PRAR or BPAR) were not associated with significant differences in the frequency of CD127 expression. Only patients with CAD had significantly lower frequencies of CD127 compared with those with no CAD (0.61 $\pm 0.549 \%$ vs. $3.08 \pm 3.375 \%, p=0.021$ ) (Figure 2), signifying that these subgroups of T-cells may play regulatory rather than effector role in transplant recipients. 
TABLE 3. Comparison between patients with and without CAD within transplanted cases (total $n=50$ )

\begin{tabular}{|c|c|c|c|c|}
\hline & & $\begin{array}{l}\text { Non-CAD } \\
(n=43) \\
\end{array}$ & $\begin{array}{c}\text { CAD } \\
(n=7)\end{array}$ & $P$-value \\
\hline Ab induction therapy & ATG/basilximab & $30 / 11$ & $4 / 1$ & 0.092 \\
\hline Ab induction therapy & No/yes & $41 / 2$ & $5 / 2$ & 0.015 \\
\hline Female/male & $\mathrm{F} / \mathrm{M}$ & $13 / 30$ & $2 / 5$ & 0.929 \\
\hline Donor sex & $\mathrm{F} / \mathrm{M}$ & $25 / 18$ & $3 / 4$ & 0.651 \\
\hline Early graft function & Good/DGF & $41 / 2$ & $7 / 0$ & 0.844 \\
\hline Current CNI type & CsA/tacrolimus & $17 / 25$ & $0 / 7$ & 0.02 \\
\hline Compliance & Yes/no & $40 / 3$ & $6 / 1$ & 0.735 \\
\hline PRAR & Yes/no & $27 / 16$ & $7 / 0$ & 0.001 \\
\hline BPAR & Yes/no & $10 / 33$ & $4 / 3$ & 0.018 \\
\hline SRAR & Yes/no & $12 / 31$ & $4 / 1$ & 0.002 \\
\hline AMR & Yes/no & $0 / 43$ & $1 / 6$ & 0.012 \\
\hline $\mathrm{GFR}\left(\mathrm{ml} / \mathrm{min} / 1.73 \mathrm{~m}^{2}\right)$ & Mean $\pm S D$ & $79.84 \pm 21.4$ & $53.86 \pm 10.15$ & 0.003 \\
\hline Serum creatinine (mg/dl) & Mean \pm SD & $0.843 \pm 0.24$ & $1.393 \pm 0.32$ & 0.000 \\
\hline PRD at 1 month $(\mathrm{mg} / \mathrm{kg})$ & Mean $\pm S D$ & $0.81 \pm 0.25$ & $0.6 \pm 0.17$ & 0.040 \\
\hline PRD at 12 months $(\mathrm{mg} / \mathrm{kg})$ & Mean \pm SD & $0.205 \pm 0.0786$ & $0.155 \pm 0.0428$ & 0.110 \\
\hline Age at transplantation (years) & Mean \pm SD & $9.79 \pm 3.653$ & $13.86 \pm 3.237$ & 0.008 \\
\hline Post-Tx duration (months) & Mean \pm SD & $29.42 \pm 14.048$ & $40.29 \pm 26.961$ & 0.107 \\
\hline Dialysis duration (months) & Mean \pm SD & $22.79 \pm 26.622$ & $18.57 \pm 16.950$ & 0.689 \\
\hline Donor age (years) & Mean $\pm S D$ & $37.42 \pm 6.641$ & $35.71 \pm 1.704$ & 0.506 \\
\hline HLA mismatch/6 & Mean $\pm S D$ & $2.38 \pm 1.545$ & $2.71 \pm 0.488$ & 0.688 \\
\hline
\end{tabular}

CAD - chronic allograft dysfunction; Ab - antibody; ATG - antithymocyte globulin; DGF - delayed graft function; CNI - calcinurin inhibitor; CSA - cyclosporine; PRAR - presumed acute rejection; BPAR - biopsy proven acute rejection; $S R A R$ - steroid resistant acute rejection; $A M R$ - antibody mediated rejection; GFR - glomerular filtration rate; $P R D$ - prednisolone; HLA - human leucocyte antigen

$P$-value was significant if $<0.05$

\section{PREDICTORS OF CAD IN TRANSPLANTED PATIENTS}

Clinical and laboratory parameters of recipients with CAD $(n=7)$ were analyzed in table 3. A significant association was found between the occurrence of CAD and the non-use of antibody induction therapy, CsA use, and occurrence of previous AR episodes with all their clinical subtypes $(p=0.015,0.02$, and $<0.05$ respectively). As expected, serum creatinine was significantly elevated, and consequently, glomerular filtration rate (GFR) was significantly lower in the CAD group $(p<0.005)$. CAD was significantly associated with lower prednisolone doses at 1 month as well as increased recipient age ( $p=0.04$ and 0.08 respectively). Logistic regression analysis demonstrated that the factors affecting the occurrence of CAD in transplanted patients were CD127\% $(\beta=-0.371, p=0.001)$, and serum creatinine level $(\beta=0.626, p=0.000)$ after adjusting other confounding factors (age and gender) (Table 4).

\section{ROLE OF CD127 IN THE PREDICTION OF CAD}

For comparison of the gross achievement of the CD127 biomarker in the prediction of CAD, distinctly of the pre-specified threshold levels, we tested the comprehensive degree of test performance using the AUROC. As shown in Figure 3, the Receiver Operating Characteristics (ROC) curve depicts the sensitivity (true positive fraction) and 1-specificity (false positive) for various levels of serum CD127. The statistically significant area under the curve $(p=0.021)$ was 0.794 , with a 95\% confidence interval of 0.633-0.954. The cutoff value of CD127\% at which CAD can be predicted is 1.305 with a sensitivity of $100 \%$ and specificity of $43 \%$ (Table 5 , Figure 3).

\section{DISCUSSION}

T-cells with a CD4-CD25 high FOXP3 phenotype (Treg) have been identified as biomarkers of tolerance in kidney transplant recipients [13]. In order to isolate Treg efficiently and to high purity, reliable markers of 
TABLE 4. Factors affecting CAD in transplant recipients based on logistic regression analysis

\begin{tabular}{|l|c|c|c|c|c|c|}
\hline \multirow{2}{*}{} & B & SE & $\beta$ & \multirow{2}{c|}{ P-value } & \multicolumn{2}{c|}{ 95\% Confidence interval for B } \\
\cline { 4 - 7 } & & & & & Lower bound & Upper bound \\
\hline Age (years) & 0.010 & 0.011 & 0.123 & 0.376 & -0.012 & 0.031 \\
\hline Donor age (years) & -0.008 & 0.006 & -0.147 & 0.171 & -0.020 & 0.004 \\
\hline Ischemia time (min) & 0.010 & 0.003 & 0.383 & 0.000 & 0.005 & 0.016 \\
\hline creatinine (mol/l) & 0.722 & 0.146 & 0.626 & 0.000 & 0.427 & 1.017 \\
\hline CD127\% & -0.039 & 0.011 & -0.371 & 0.001 & -0.061 & -0.016 \\
\hline Gender (M/F) & 0.072 & 0.079 & 0.099 & 0.368 & -0.088 & 0.232 \\
\hline CNI (CsA/tacrolimus) & 0.008 & 0.063 & 0.012 & 0.903 & -0.120 & 0.136 \\
\hline Induction therapy & 0.028 & 0.063 & 0.047 & 0.656 & -0.099 & 0.155 \\
\hline
\end{tabular}

CNI - calcinurin inhibitor; CSA - cyclosporine; $P$-value was significant if $<0.05$

TABLE 5. Value of the area under the curve of CD127 percentage in CAD children

\begin{tabular}{|c|c|c|c|c|}
\hline CD 127 levels & \multicolumn{2}{|c|}{ Sensitivity } & \multicolumn{2}{|c|}{ 1-Specificity } \\
\hline 0.7000 & \multicolumn{2}{|c|}{0.667} & \multicolumn{2}{|c|}{0.214} \\
\hline 1.3050 & \multicolumn{2}{|c|}{1.000} & \multicolumn{2}{|c|}{0.429} \\
\hline Area & $\mathrm{SE}^{\mathrm{a}}$ & Asymptotic Sig. ${ }^{b}$ & \multicolumn{2}{|c|}{ Asymptomatic $95 \% \mathrm{Cl}$} \\
\hline \multirow[t]{2}{*}{0.794} & \multirow[t]{2}{*}{0.082} & \multirow[t]{2}{*}{0.021} & Lower bound & Upper bound \\
\hline & & & 0.633 & 0.954 \\
\hline
\end{tabular}

${ }^{a}$ Under the nonparametric assumption

${ }^{b}$ Null hypothesis: true area $=0.5$

$P$-value $<0.5$ was considered significant

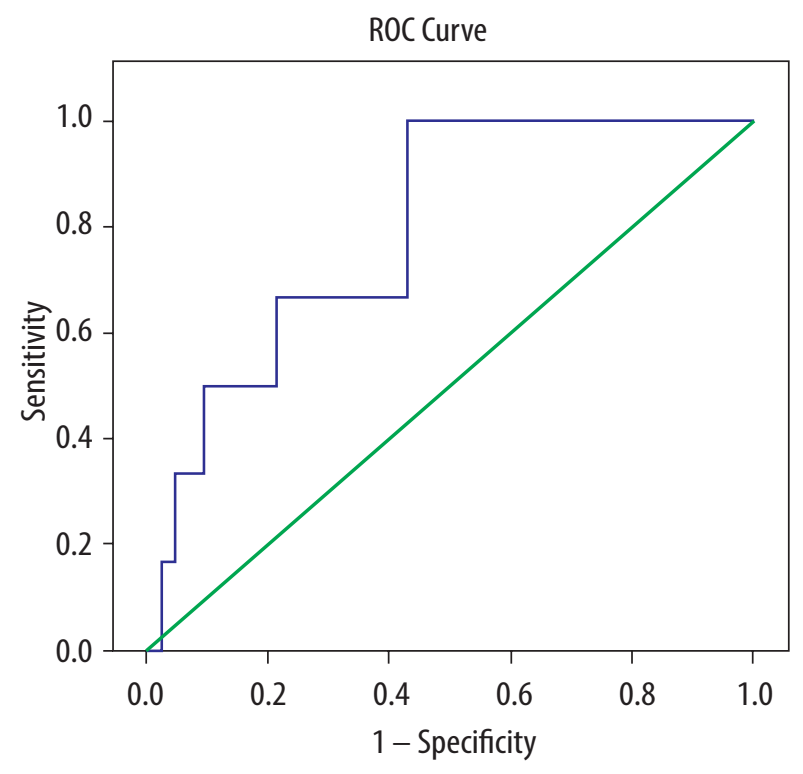

Area under the curve

FIGURE 3. ROC curve analysis of CD127 percentage in CAD children. The statistically significant area under the curve $(p=0.021)$ was 0.794 , with a $95 \%$ confidence interval of $0.633-0.954$. The cutoff value of CD127\% at which CAD can be predicted is 1.305 with a sensitivity of $100 \%$ and specificity of $43 \%$. $P$-value was significant if $<0.05$

identification are required. Given the non-specificity of CD25 and FoxP3 expression, a number of other markers have been explored. Of these markers, CD127 is cur- rently one of the most useful. The benefit of CD127 is that a population of Tregs can be isolated by negative selection alone without the need for CD25 positive selection [14]. The aim of this work was to study the expression of IL-7 receptor (CD127) in peripheral T cells of pediatric kidney transplant recipients \& to detect the association between CD127 surface marker and the development of rejection among this group of patients.

We found that the absolute number of $\mathrm{T}$ cells with the surface marker of CD127 was significantly higher in the transplanted population than normal controls after a mean post Tx duration of $30.9 \pm 16.5$ months. This finding is in agreement with previous data in the literature [15-17]. Pablo et al. studied circulating lymphocyte subsets after KT. They found that the percentage of CD127low T cells in patients with stable graft function was decreased at 0.5 and 2 years after KT in comparison to healthy individuals. However, they increased in the time approaching similar values to those in healthy individuals at 5 years post-Tx [18]. So, it seems that the T cell subset distribution in transplant recipients is a dynamic process and that it is not only differed by the different clinical situations but also by post-Tx duration.

Seddiki et al. [19] and Liu et al. [4] demonstrated that CD127 is downregulated on all human T cells after activation and, in contrast with the reported re-expression of CD127 on the majority of peripheral memory and effector T cells, Treg CD4+CD25 Foxp3+ cells remain CD127 low. Constitutively reduced expression 
of CD127 in Tregs may result from the Foxp3 interaction with the CD127 promoter that reduces the expression of CD127 in this subset [4]. On the other hand, Foxp3 induced by activation in effector T cells is not sufficient to permanently suppress CD127 expression in these cells and after the initial, post-activation decline of CD127 expression in Teff cells CD127 is reconstituted $[6,20]$.

In the current study; the expression of CD127 in patients with AR was not significantly different from that in patients without AR. Furthermore, we found a higher percentage of CD127 cells in recipients without CAD than those with CAD signifying that these subgroups of T-cells $(\mathrm{CD} 127+)$ may play a regulatory rather than effector role in transplant recipients.

Many previous reports did not support our finding $[15,16,21,18]$. Codarri et al. [15] and Vallotton et al. [16] showed that T cells expressing interleukin-7 receptor a (IL-7Ra; CD127) contain allospecific cells that expand in the peripheral blood compartment of patients with chronic rejection more than in patients without chronic rejection. Furthermore, an increased number of CD127 cells and a decreased number of FoxP3+ regulatory $\mathrm{T}$ cells have been associated with $\mathrm{CHR}$ in renal transplant recipients [21]. Pablo et al. [18]; demonstrated that although CD127 expression is decreased after 5 years post-Tx in recipients with stable graft function, it increases again in children with CAD.

On the other hand, Klein et al. supported our finding by reporting that a high frequency of CD127low/cells did not express FOXP3 and, conversely, that there was a high proportion of FOXP3-expressing CD1271ow cells in healthy individuals [22], suggesting that these markers did not represent the same population of Tregs and need further studies.

Indeed, in a murine kidney allograft model, a higher and sustained level of Foxp3+ regulatory $\mathrm{T}$ cells has been demonstrated in tolerated compared with rejecting allografts. However, the presence of Foxp3+ regulatory $\mathrm{T}$ cells in human renal allografts was less clearly associated with stable function $[23,24,18]$. Hence, the clinical significance of changes in percentages of circulating CD4+ regulatory $\mathrm{T}$ cells after transplantation is not yet clear.

The discrepancy in the previous reports and our results might be explained by the fact that our included patients with CAD were few (only 7 recipients, 1 patient with $\mathrm{cAMR}$ and 6 patients with chronic allograft nephropathy). In addition; changes in these activated CD25+ CD4+ T-cell populations are caused by other factors as HCV infection. Finally, differences in the cumulative dosages of IS therapy may influence results from this type of studies [25].

cAMR gradually becomes the most important cause of dysfunction in the late period of renal graft, and there is no viable clinical prophylaxis or treatment [26]. The follicular helper T cell (Tfh cell) is important in the generation and the development of cAMR, as it aids
B cell differentiation into plasma cells and the production of donor-specific antibody (DSA) through the secretion of IL-21 [27]. The number of Tfh cells in the patient is consistent before and after renal transplantation, but their ability for IL-21 secretion decreases dramatically after renal transplantation, suggesting that immunosuppressive therapy may affect Tfh cell function and phenotypic change [28].

Although we failed to find a significant association between CD127 expression and the types of IS drugs used; Mammalian target of rapamycin-inhibitors (m-TORI) are shown to selectively spare CD4+ regulatory T cells [29]. Also, CNIs (CsA and tacrolimus) may exert different effects on regulatory T-cell numbers [30]. It was reported previously that CNIs have a markedly negative impact on graft tolerance by affecting Treg function and survival, mainly by interfering with IL-2 production $[31,32]$. Conversely, corticosteroids have been reported to increase Treg frequency and FOXP3 expression in patients with autoimmune diseases $[33,34]$. In addition, renal transplant recipient received MMF showed significantly higher CD4+CD25hiFOXP3+ Tregs compared to patients on other treatments [32]. More recently it has been demonstrated that the treatment with MMF, Tacrolimus, and methyl-prednisolone, but not m-TORI, decreased Treg viability and proliferation [35].

Our study is limited by the fact that it was conducted in a single institution with small sample size. Also, the study lacks sequential analysis of CD127 lymphocyte expression at different time intervals post-Tx.

Despite these limitations, our results nevertheless indicate that circulating CD4+CD127 T cells is a potential novel immune marker for CAD. External validation of circulating CD4+CD127 T cell as a predictor of CAD could eventually guide organ allocation and therapeutic interventions aimed at individual-specific targets of Treg cell.

\section{CONCLUSIONS}

The percentage of CD127+ T cell subset is highly expressed in pediatric renal transplant recipients than normal subjects. CD127+ cells expression significantly increased in transplanted children with stable graft function than those with CAD. CAD might be associated with a deficient percentage of CD127 and it could be helpful to monitor these cells in estimating the immune status of pediatric kidney transplant recipients to make convenient preventive strategies. The cause-effect mechanism between CD127+ cells low percentage and the CAD is a subject for further large cohort studies.

\section{ACKNOWLEDGMENT}

This work was supported by NRC, in Egypt, the grant number is 10010008 . 


\section{DISCLOSURE}

The authors declare no conflict of interest.

\section{REFERENCES}

1. Nankivell BJ, Alexander SI. Rejection of the kidney allograft. N Engl J Med 2010; 363: 1451-1462.

2. Zheng Y, Rudensky YA. Foxp3 in control of the regulatory T cell lineage. Nature Immunology 2008; 8: 457-462.

3. Kitamura N, Murata S, Ueki T, et al. Co-stimulation can abrogate Foxp3+ regulatory $\mathrm{T}$ cell mediated suppression of antitumor immunity. Int J Cancer 2009; 125: 630-638.

4. Liu W, Putnam AL, Xu-yu Z, et al. CD127 expression inversely correlates with FoxP3 and suppressive function of human CD4+ T reg cells. J Exp Med 2006; 203: 1701-1711.

5. Allan SE, Crome SQ, Crellin NK, et al. Activation-induced FOXP3 in human $\mathrm{T}$ effector cells does not suppress proliferation or cytokine production. Int Immunol 2007; 19: 345-354.

6. Ciebiada M, Kasztalska K, Gorska-Ciebiada M, et al. Expression of IL-7 receptor in human peripheral regulatory T cells. Arch Med Sci 2013; 9: 555-560.

7. Huang PC, Yang CY, Lee CY, et al. Pediatric renal transplantation: Results and prognostic factors Asian J Surg 2013; 36: 53-57.

8. Fleiner F, Fritsche L, Glander P, et al. Reporting of rejection after renal transplantation in large immunosuppressive trials: biopsy-proven, clinical, presumed, or treated rejection? Transplantation 2006; 81: 655-659.

9. Chapman JR, O'Connell PJ, Nankivell BJ. Chronic renal allograft dysfunction. J Am Soc Nephrol 2005; 16: 3015-3026.

10. Solez K, Colvin RB, Racusen LC, et al. Banff 07 classification of renal allograft pathology: updates and future directions. Am J Transplant 2008; 8: 753-760.

11. Fadel FI, Elghoroury EA, Elshamaa MF, et al. Lymphocyte Activation Markers in Pediatric Kidney Transplant Recipients. Int J Biomed Sci 2015; 11: 121-130.

12. Ekong UD, Luo X, Yu M, et al. Lymphocyte activation markers may predict the presence of donor specific alloreactivity in pediatric living related liver transplant recipients. Hum Immunol 2011; 72: 392-397.

13. Lopez-Hoyos M, Segundo DS, Fernández-Fresnedo G, et al. Regulatory $\mathrm{T}$ cells in renal transplantation and modulation by immunosuppression. Transplantation 2009; 88: S31.

14. Issa F Wood KJ. CD4+ regulatory T cells in solid organ transplantation. Curr Opin Organ Transplant 2010; 15: 757-764.

15. Codarri L, Vallotton L, Ciuffreda D, et al., Expansion and tissue infiltration of an allospecific CD4+ CD25+ CD45RO+ IL-7Rahigh cell population in solid organ transplant recipients. J Exp Med 2007; 204: 1533-1541.

16. Vallotton L, Hadaya K, Venetz JP, et al. Monitoring of CD4+ CD25high IL-7Rahigh activated T cells in kidney transplant recipients. Clin J Am Soc Nephrol 2011; 6: 2025-2033.

17. Alonso-Arias R, Suárez-Alvarez B, López-Vázquez A, et al. CD127low expression in CD4+ CD25high T cells as immune biomarker of renal function in transplant patients. Transplantation 2009; 88: S85-S93.

18. Pablo J E, van de Berg J, Hoevenaars EC, et al. Circulating lymphocyte subsets in different clinical situations after renal transplantation. Immunology 2012; 136: 198-207.

19. Seddiki N, Santner-Nanan B, Martinson J, et al. Expression of interleukin (IL)-2 and IL-7 receptors discriminates between human regulatory and activated T cells. J Exp Med 2006; 203: 1693-1700.
20. Allan SE, Crome SQ, Crellin NK, et al. Activation-induced FOXP3 in human $\mathrm{T}$ effector cells does not suppress proliferation or $\mathrm{cy}$ tokine production. Int Immunol 2007; 19: 345-354.

21. Warnecke G, Bushell A, Nadig SN, Wood KJ. Regulation of transplant arteriosclerosis by CD25+CD4+ T cells generated to alloantigen in vivo. Transplantation 2007; 83: 1459-1465.

22. Klein S, Kretz CC, Krammer PH, Kuhn A. CD127 (low/-) and Fox P3 (1) expression levels characterize different regulatory T-cell populations in human peripheral blood. J Invest Dermatol 2010; 130: 492-499.

23. Veronese F, Rotman S, Smith RN, et al. Pathological and clinical correlates of FOXP3+ cells in renal allografts during acute rejection. Am J Transplant 2007; 7: 914-922.

24. Yapici U, Bemelman FJ, Scheepstra CG, et al. Intragraft FOXP3 protein or mRNA during acute renal allograft rejection correlates with inflammation, fibrosis, and poor renal outcome. Transplantation 2009; 87: 1377-1380.

25. Fourtounas C, Dousdampanis P, Sakellaraki P, et al. Different immunosuppressive combinations on T-cell regulation in renal transplant recipients. Am J Nephrol 2010; 32: 1-9.

26. Westall GP, Paraskeva MA, Snell GI. Antibody-mediated rejection. Curr Opin Organ Transplant 2015; 20: 492-497.

27. Shi J, Luo F, Shi Q, et al. Increased circulating follicular helper $\mathrm{T}$ cells with decreased programmed death-1 in chronic renal allograft rejection. BMC Nephrol 2015; 16: 182.

28. de Graav GN, Dieterich M, Hesselink DA, et al. Follicular T helper cells and humoral reactivity in kidney transplant patients. Clin Exp Immunol 2015; 180: 329-340.

29. Hester J, Mills N, Shankar S, et al. Th17 cells in alemtuzumab-treated patients: the effect of long-term maintenance immunosuppressive therapy. Transplantation 2011; 91: 744-750.

30. Tsaur I, Gasser M, Aviles B, et al. Donor antigen-specific regulatory T-cell function affects outcome in kidney transplant recipients. Kidney Int 2011; 79: 1005-1012.

31. Miroux C, Morales O, Ghazal K, et al. In vitro effects of cyclosporine $\mathrm{A}$ and tacrolimus on regulatory $\mathrm{T}$-cell proliferation and function. Transplantation 2012; 94: 123-131.

32. Fourtounas C, Dousdampanis P, Sakellaraki P, et al. Different immunosuppressive combinations on T-cell regulation in renal transplant recipients. Am J Nephrol 2010; 32: 1-9.

33. Braitch M, Harikrishnan S, Robins RA, et al. Glucocorticoids increase CD4CD25 cell percentage and Foxp3 expression in patients with multiple sclerosis. Acta Neurol Scand 2009; 119: 239-245.

34. Karagiannidis C, Akdis M, Holopainen P, et al. Glucocorticoids upregulate FOXP3 expression and regulatory $\mathrm{T}$ cells in asthma. J Allergy Clin Immunol 2004; 114: 1425-1433.

35. Scottà C, Fanelli G, Hoong SJ, et al. Impact of immunosuppressive drugs on the therapeutic efficacy of ex vivo expanded human regulatory T cells. Haematologica 2016; 101: 91-100. 